O homem Moisés e a religião monoteístaTrês ensaios: o desvelar de um assassinato

Betty Bernardo Fuks Rio de Janeiro: Civilização Brasileira, 2014, 210 págs.

\title{
A última interpretação freudiana da religião
}

Bruno Pinto de Albuquerque*

Ao longo de sua gigantesca obra, Sigmund Freud sempre se interessou por estudar os mais variados fenômenos psíquicos e sociais partindo da clínica psicanalítica que inaugurou. Esta se constitui fundamentalmente em um método de investigação e tratamento psíquico, cuja direção é regida pela ética da singularidade. O psicanalista em seu ofício oferece uma escuta cuja atenção é flutuante para deixar sempre aberta a possibilidade de que a fala do sujeito soe estrangeira. A clínica freudiana, construída ela mesma a partir de articulações com muitos outros campos do saber, insiste na aposta de que aquele que decide correr os riscos e pagar o preço da empreitada possa ter algum acesso a essa alteridade radical presente naquilo que possui de mais íntimo. É a abertura para este inominável, mais além da fantasia que recorta com o sentido o mistério inesgotável da vida, que pode aliviar o sintoma do neurótico que sofre pelo excesso de respostas.

Partindo de sua experiência clínica, Freud se aventurou por vários campos, costurando com o conceito de inconsciente o elo perdido

* Mestrando da Universidade do Estado do Rio de Janeiro - UERJ (Rio de Janeiro, RJ, Br). 


\section{RESENHAS BIBLIOGRÁFICAS}

entre psiquismo e cultura. Entre eles, a religião, para a qual ele construiu diferentes chaves de compreensão, sempre ocupou um lugar significativo. O último grande escrito publicado por Freud em vida foi o texto sobre o qual Betty Fuks se debruça, com elegante erudição, para dar prosseguimento ao seu percurso de trabalho no campo da abordagem psicanalítica da religião. A autora sustenta a importância do texto que "contém a última versão do pensamento psicanalítico sobre religião" (p. 30), valorizando sua "relevância e magnitude clínica, teórica e política" (p. 36).

Traçando conexões entre diferentes tempos da obra freudiana, Betty Fuks explora os desdobramentos da aposta feita por Freud de investigar a história de Moisés por meio dos instrumentos de desvelamento dos processos inconscientes que construiu a partir da técnica psicanalítica. Ao ler a história mosaica como lê o inconsciente, ou seja, tratando os registros como uma rede de traços de memória, Freud constrói uma ficção teórica que não deixa de manter um caráter científico, na qual retoma elementos de toda a sua obra para fazê-los trabalhar.

O que o levou a essa empreitada foi a busca de explicações na religião judaica para o ódio aos judeus, que crescia assustadoramente com a ameaça nazista na Europa da década de 1930. Entre as múltiplas origens do antissemitismo identificadas por Freud, tais como a associação da circuncisão com o complexo de castração e a crença judaica na eleição divina, destaco aqui a ênfase dos judeus na impossibilidade de representação de Deus, que 'sem rosto e sem imagem é o estrangeiro dos estrangeiros'. Ex-timo a seu próprio povo, ocupa o lugar de um verdadeiro 'continente estrangeiro' na economia libidinal dos homens" (p. 165-166). O judeu no texto de Freud pode ser tomado como uma das figuras paradigmáticas do excluído, segregado pelo horror à diferença que $o$ constitui. O sujeito, que Jacques Lacan localizou na instância do isso, insiste com o desejo inconsciente, provocando horror à instância do eu, que constrói de si uma versão idealizada e hostiliza o sujeito, tratando-o como marginal. A equivalência entre a constituição de um sujeito e de um povo se sustenta na medida em que ambos delineiam seus próprios contornos a partir da alteridade, o que revela a lógica paradoxal do inconsciente.

Como Betty Fuks assinala, o texto de Freud é também uma tentativa de responder ao porquê de a religião não ter desaparecido com o Iluminismo. Considerada por ele uma ilusão, a religião foi a única que resistiu aos ferozes ataques das luzes da razão. A autora aponta que Lacan, em "Ciência e verdade", indica que, quanto mais a ciência exclui o sujeito do inconsciente, mais a religião ganha terreno. Ela mostra que a crítica de Freud se dirige a discursos fundamentalistas que tentam impedir as pessoas de pensar por si próprias. A aposta freudiana consiste em oferecer um lugar para o sujeito em análise que suporte a equivocidade das palavras e a pluralidade de sentidos. "A paixão pelo estranho, 
o inassimilável do saber inconsciente, o desapego pelo idêntico e por verdades apriorísticas, levou-o a atrelar sua escuta à inesgotável melodia da pulsão, um dos conceitos que instalou, e mantém no campo da psicanálise o lugar inexpugnável da alteridade" (p. 122).

A experiência de acompanhar o estilo próprio da escrita criativa de Betty Fuks nos faz testemunhar a amplitude de sua leitura do texto freudiano. Esta é ainda enriquecida pelo convite que faz a importantes autores para entrar na dança: Jacques Lacan, Hanna Arendt, Michel Foucault, Jacques Derrida e Emmanuel Lévinas, entre outros - a bibliografia, com articulações interessantes e inesperadas, é extensa e rica. Seu livro discute ainda muitas outras temáticas, como a condição dos judeus após o nazismo e o deslocamento para utopias políticas da esperança de proteção contra o desamparo. Concentrei minhas considerações no que tange à religião, mas, como a própria autora sustenta, o texto de Freud é uma obra aberta, onde cabe a cada leitor abrir suas páginas e fazer seu próprio trajeto pelas linhas da última interpretação freudiana da religião.

Citação/Citation: Albuquerque, B.P. de (2016, março). A última interpretação freudiana da religião. Resenha do livro $O$ homem Moisés e a religião monoteísta - Três ensaios: o desvelar de um assassinato. Revista Latinoamericana de Psicopatologia Fundamental, 19(1), 186-188.

Editor do artigo/Editor: Profa. Dra. Sonia Leite

Recebido/Received: 14.9.2015/ 9.14.2015 Aceito/Accepted: 29.10.2015 / 10.29.2015

Copyright: (C) 2009 Associação Universitária de Pesquisa em Psicopatologia Fundamental/ University Association for Research in Fundamental Psychopathology. Este é um artigo de livre acesso, que permite uso irrestrito, distribuição e reprodução em qualquer meio, desde que $\mathrm{o}$ autor e a fonte sejam citados / This is an open-access article, which permits unrestricted use, distribution, and reproduction in any medium, provided the original authors and sources are credited.

\section{Bruno Pinto de Albuquerque}

Mestrando em Psicanálise pelo Programa de Pós-Graduação em Psicanálise, da Universidade do Estado do Rio de Janeiro - UERJ (Rio de Janeiro, RJ, Br); Bolsista CAPES

Rua São Francisco Xavier, 524 - Maracanã

20550-900 Rio de Janeiro, RJ, Br

e-mail: brunopintodealbuquerque@gmail.com

\section{(cc) BY-NC}

This is an open-access article, which permits unrestricted use, distribution, and reproduction in any medium for non-commercial purposes provided the original authors and sources are credited. 